\title{
The case of Sofia: an example of the dynamic properties of the therapeutic relationship
}

\author{
Laura Barca1, Monica De Marchis² \\ 1 Institute of Cognitive Sciences and Technologies, National Research Council, Rome, Italy \\ 2 Centro Multiverso, Rome, Italy
}

Keywords: Post-rationalist cognitive perspective; treatment setting; therapeutic relationship

\section{Summary}

From a constructivist, post-rationalist cognitive perspective the core of any clinical intervention is attention to relationships and ways of assigning meaning to the world. After a brief discussion of recent evidence regarding the healing role of ruptures in the therapeutic relationship and its dynamical properties, a clinical case is illustrated. The case is presented by outlining some of the key "decision points" faced jointly by client and therapist, both of whom are actively involved in dynamically constructing a shared relational space. Each actor in this process has a unique perception of reality, but all are faced with jointly constructing a therapeutic relationship. In this process, the reciprocal legitimation and continuous flow between the actors' mind states helps individual meanings and experiences to emerge in their shared and unique interpersonal space. The current case provides information about the multifaceted aspect involved in reconstructing therapeutic alliance after a period of impasse.

\section{Introduction}

This paper addresses the dynamic properties of the therapeutic relationship. By means of clinical exemplification it shows how this relationship can change over time depending on the symmetries/asymmetries in the client's and the therapist's emotional positions, i.e., the two sides of this particular type of interpersonal connection.

The first step toward constructing and establishing an effective therapeutic relationship is to define a unique and unambiguous clinical space (i.e., therapeutic setting), which is co-built and shared by both actors in this relationship. Among the different theoretical and clinical 
perspectives, the constructivist approach emphasizes the importance of human relationships in psychotherapeutic processes (Mahoney, 2005; Mahoney \& Granvold, 2005). In the constructivist framework, the post-rationalist paradigm strongly emphasizes the active involvement of both therapist and client in building a shared clinical space right from the first sessions of the therapy (Balbi, 2008; Guidano, 1991; 1995; Nardi, 2010; Nardi \& Bellantuono, 2008; Nardi et al., 2012a; Nardi et al., 20102b). The first therapeutic act in defining this shared space is implemented by redefining the client's problems so that both actors in the relationship can share them in generative terms (De Marchis, 2008). Based on this shared workspace, which is actively co-built by client and therapist, a generative alliance can be established. The foundation of this setting begins during the first sessions and is actively and dynamically redefined and re-negotiated during the course of therapy.

One of the most consistent results of recent research on the efficacy of psychotherapy is that the quality of the therapeutic relationship is a good predictor of a positive outcome (Greenberg \& Pascual-Leone, 2006; Muran \& Safran, in press; Reda, Donati della Lunga \& Canestri, 2011; Samstag et al., 1998, Samstag et al., 2008). A number of clinical cases reported in the literature highlight the healing role of a collaborative and empathic relationship, in which therapists support clients as they explore their emotional experiences (Greenberg, 2008; Lindeman, 2011; Neimeyer et al., 2008; Timulak \& Pascual-Leone, 2014). The stability of the relationship is crucial to ensure a positive course of treatment. However, the key element seems to be the therapist's capacity to re-establish positive and generative tuning with the client after a period of impasse (i.e., a break in the collaborative process accompanied by a deterioration in communication and impoverished narratives) (Safran, Muran \& Shaker, 2014). Thus, the morphology of a therapeutic relationship can be described in terms of alternating periods of approach-avoidance between two (emotional) systems in which the approach-phases correspond to greater tuning and sharing of a common emotional space and the avoidancephases correspond to periods of impasse and less tuning.

Considering the period of impasse, indicators of a crisis in the relationship can be found in the behaviors of both actors in the relationship. In the case of the client, for example, there might be an explicit or implicit (e.g., through sarcasm) communication of distrust in the relationship, or a compliant but not genuinely collaborative attitude. In the case of the therapist, feelings of discomfort, confusion or frustration during the session might signal a period of reduced tuning with the client. Thus, looking at the emotional activations of both actors of the relationship (e.g., not only the client but also the therapist) is crucial to identify an incoming stalemate in the process.

The following clinical case is an illustration of the dynamics of this process. The case material is organized around one pivotal event that occurred at an advanced stage in therapy, i.e., when the client decided to use anoretic drugs to lose weight. One of the authors of this paper was the therapist. The stability and temporal continuity of the therapy allowed formulating longitudinal reflections about the interpersonal processes that were occurring in this relationship, as it unfolded over three years (approximately 90 sessions). Thus, the temporal dimension was crucial in this case, because it allowed visualizing how oscillations in the alliance and clinical setting mirrored important emotional-psychological-behavioral changes in both the client and the therapist.

\section{Case introduction}

At the beginning of the therapy, the client, Sofia (pseudonym), was a woman in her early 50s. She was overweight and shabbily dressed. She worked in the administrative office of a clinic. The client had no previous history of psychotherapy. She was referred by a psychiatrist who was prescribing her medication for mood disorders. Sofia's medical report indicated a clinical 
picture of "dis-regulation of eating behavior, with a peak in depression following the death of her father".

\section{Presenting complaints}

Her presenting complaints primarily involved "feeling like a mosaic falling apart, since my father's death after a long illness" (an event that occurred 3 years before the first meeting). She described profound difficulties in managing emotional activations and interpersonal problems as she often experienced a sense of intrusion from other people and their criticisms. The emotional activations that Sofia experienced in relating to others produced an untenable "internal chaos" which she could only allay by eating (i.e., binge eating behavior) ${ }^{1}$, a dysfunctional behavior aimed at avoiding negative feelings.

\section{History}

Sofia grew up with her parents and two sisters in Italy. She described an authoritarian, jealous and violent father whom she did not oppose until adulthood. He was her point of referent as her mother was a little affectionate, dealing only with practical things and with obsessive traits for house cleaning. Her father died in 2007 after a long illness, her mother and sisters are still alive. As a child, she followed the rules and disciplines to the letter and was very timid. She tells about a wall she had with others (both in family and outside), thus reports only few friendships during middle school.

Sofia was in an unsatisfactory marriage and had two children from it: a 24-year- old male and a 14-year-old female. She was unwilling to speak about her husband and their marriage. By contrast, she idealized her relationship with her children, which according to her was characterized "by maximum confidence and maximum respect", especially with regard to the firstborn, Andrea.

\section{Assessment}

Sofia received an evaluation following a semi-structured clinical interview. The first interview focused on collecting information about the patient's actual complaints, the problematic areas and the context in which they occur, the resources she has and the motivation to undertake psychotherapy. Over the course of therapy, the verbal assessment focused on depressive symptoms and eating behavior.

Generally, the client was well oriented in time and space and had good contact with reality. However, her reconstruction of problematic events (both past and recent) was extremely fragmented and discontinuous, with many memory lapses. Sofia had profound difficulty in creating space-time sequences of events and in describing her inner states, particularly her emotional experiences. She had a deficit in narrative integration; in fact, her narratives were often circumstantial, so she tended to linger over the description of facts and contingencies, lost in her own reasoning (Neimeyer, 2000; Dimaggio \& Semerari, 2001). No structured assessment

\footnotetext{
${ }^{1}$ It is interesting to note that initially Sofia did not mention food dysregulation as a problem to work on in therapy, probably because the eating symptom was still an egosyntonic behavior.
} 
measures were applied during the process, but along with eating problems and depression, she manifested dependent personality traits. Based on the information gathered during the sessions, the diagnostic impression is consistent with Unspecified Mood (Affective) Disorder (F39 [296.90]; DSM IV-TR; American Psychiatric Association, 2000). As for the eating behavior, an impression of Unspecified Eating Disorder (F50.9, [307.50]) has been formulated. This category includes those disorders that do not meet all the criteria for any specific eating disorder, such as Binge Eating Disorder, which is characterized by recurrent episodes of binge eating without regular inappropriate compensatory actions typical of bulimia nervosa.

\section{Case conceptualization from a post-rationalist approach}

In the framework of a post-rationalist paradigm, Sofia can be described as an outward eating disorder-prone stile of personal identity, focusing on external referential contexts to recognize and regulate emotional experiences (Arciero \& Bondofli, 2009; Bertolino et al., 2005; Guidano, 1991, 1995; 2007; Mazzola et al., 2014; Nardi, 2010; Nardi et al., 2012; Nardi \& Bellantuono, 2008; Rubino et al., 2007). Several of Sofia's characteristics led to this hypothesis. The first element was her difficulty in managing interpersonal boundaries. This difficulty manifested in her relationships with family members, whom she described as exceedingly intrusive, and also in the clinical setting with the therapist, where she needed to create a physical demarcation with the therapist during their first meeting. Consistently with an outward-contextualized style, the client had profound difficulty in focusing on her internal states (e.g., emotions and feelings), and typically used an external point of reference to decode them and continuously tuning with the others. She largely neglected the subjective content of emotional states (e.g., bodily experiences, mood oscillations, feelings and related mental images), and the only description she provided was 'feeling like a boat at the mercy of a storm'. Sofia's mode of processing emotional experiences (e.g., by means of constant redefinition based on information gathered from referential contexts) has several emotional consequences. These include the emergence of a sense of inadequacy in the case of sloppy correspondence between her expectations and others' responses, a sense of emptiness and dissolution when the other is unavailable as a point of reference and a sense of intrusion when the other is perceived as too defining and critical (Nardi, 2008; Zaratti \& De Marchis, 2007; De Marchis \& Barca, 2013).

Sofia's difficulties in managing and regulating her discrepant emotions that were generated from interpersonal relationships seemed critical right from the first therapy sessions. She tried to give order to the messy state generated by her discrepant emotions by means of an external element, i.e., food. Consistent with this way of organizing experiences and meanings, the use of food allows her to control emotional activations by flattening them, virtually eliminating the resulting emotions into undefined elements (i.e., "internal chaos"). She used food as an anesthetic to block her emotions, especially those she identified as anger ${ }^{2}$. Progressively in

\footnotetext{
2 Part of Sofia's therapy has been devoted to a greater structuring of her own personal experience of 'being angry'. For example, by identifying the triggers of her anger and how it develops (e.g., how she realizes she is angry and which thoughts, mental images and bodily experiences precede and accompany this feeling). This is an important step for Sofia. By making this effort, she is able to interpret her feelings differently and, more generally, has developed a different view of herself in the world (e.g., she no longer says 'I am a person who gets angry', but rather 'I am a person who protests' which led, for example, from a sense of helplessness).
} 
addition to using food to manage her feelings of emptiness and blurry emotional activations, she also underwent Intragastric Balloon obesity surgery; in fact she was on the waiting list for another one before the beginning her therapeutic path. The mechanism underlying these behaviors seems redundant: she uses (or introduces) an external element to control her internal states; these are blurry perceptions which, as such, are poorly actionable.

Breakdown of Sofia's personal coherence.

During a person's lifespan, some emotional experiences might occur that cause a breakdown in personal coherence and in the continuity of one's sense of self. These perturbations create discrepancies in the internal coherence of the system (i.e., the self) that push towards a reorganization of the system. This process occurs through the assimilation of perturbations, resulting in an increase in the system's complexity. These perturbations also constitute an important drive towards personal development. Based on the system's level of self-awareness, the reorganization can lead to personal growth or (in the case of poor awareness) toward a breakdown of the system and emotional disturbances (i.e., symptoms) (Guidano, 1991; 1995; Zaratti \& De Marchis, 2007; Arciero \& Bondolfi, 2009). In the case of Sofia, the first event which led to a breakdown was grieving for her father, which she experienced as loss of the reference point from which she derived a consistent and stable sense of self. The absence of another acting as a hub through which she obtained access to understanding her emotional experiences generated a sense of emptiness and fragmentation in Sofia that was controlled by the manipulation of food and by looking for a new benchmark in her husband and (given his inadequacy in responding to Sofia's new requests) in her children.

A more recent breakdown of Sofia's system, i.e., the emotional discrepancy linked to her children growing up, was less noticeable to her but perhaps more painful because it left her unguarded. Indeed, Sofia experienced this as a sort of 'empty nest' syndrome (Defey et al., 1996). Her request for psychotherapy and her marital crisis coincided with the increasing distance between her and her children. Moreover, the increasing distance from her children occurred at a period of life that was physiologically stressful for her, i.e., in conjunction with the menopause (Deek, 2003; Defey et al., 1996).

Thus, it can be assumed that after her father's death Sofia turned to her husband as an external reference point and that her children (even more than her husband) were a source of stability and positive self-image. When her children started to naturally distance themselves, Sofia again felt unguarded in her relationship with a disappointing husband who was probably unable to help her fulfill her needs; therefore, she sought a new external point of reference in psychotherapy.

\section{Course of the treatment}

The critical period in the therapeutic relationship occurred at an advanced stage of therapy (10th month) and lasted for several sessions. In previous months, the client had shown a number of improvements such as an increase in self-reflexive capacity and relational modifications (i.e., greater assertiveness towards her children and husband) and greater acceptance and validation of unpleasant emotions resulting in a reduction of her eating dysfunction (i.e., reduced frequency of using food as a regulator of internal states).

\section{Complicating factor}

The problematic event concerned the use of pharmacological therapy to reduce body weight, which was based on taking amphetamines (for a review of pharmacological treatments for obesity see also Ioannides-Demos, Piccenna \& McNeil, 2011). According to Ioannides et al. 
(2011), only two drugs are currently approved for long-term treatment of obesity; in fact, serious concern for patients' safety has led to the withdrawal of some drugs from the market. Even more problematic in Sofia's case was the fact that her cardiologist had prescribed the drug therapy without prior consultation with the psychotherapist or the psychiatrist who had been following her for some time. The possibility of a negative interaction between the two pharmacological treatments raised serious concerns about the client's well-being. Furthermore, while she was taking these anoretic drugs Sofia experienced a period of renewed energy, but she also experienced side effects (e.g., restlessness and nervousness, irritability and insomnia), which led to additional difficulties in managing her interpersonal relationships. Drug therapy was a stress factor in the therapeutic relationship at several different levels. First, the client felt that these drugs were the only source of her new positive feelings. She underestimated previous therapeutic work and put herself back into a passive position with respect to her emotional experiences (i.e., she attributed the change to the drug, which was an external factor). Efforts were made to move from 'externality' to 'internality', where Sofia was the author of her changes. Second, the effect of the drugs actually influenced therapy by affecting Sofia's narratives, which were again chaotic and extremely rigid. During the narratives, she had to follow her own logical sequence and, if interrupted, she got nervous, and lost the cooperative position she had laboriously built. Moreover, often during the same session Sofia started to fluctuate between a demand for care and nurturance and a competitive system. Due to the amphetamines, Sofia was experiencing new energy, but she was also paying for it with greater insecurity in her behaviors and choices. Sofia's typical way of organizing experiences using an outward-contextual style often led her to ask for reassurance and advice, e.g., about whether to send text messages to her daughter and their contents. The therapist's congruent emotional reaction was characterized by feelings of irritation, anger and frustration, which could not be acted out as such during the session without a generative and proactive drive.

Taking into account the contextual environment of the relationship, the event which caused a high level of distress to the therapeutic relationship originated in the client's life context. The fact that the client was taking drug therapy which had disputed legal validity and had been proven to be clinically dangerous caused emotional fluctuations in both actors of the relationship; this led to a critical phase with high levels of confusion. In this situation, the therapist's life context provided the repair. Through intensified supervision, in-session interpersonal processes were analyzed (Hill \& Knox, 2009; Neimeyer et al., 2015) and it was possible to develop the therapist's frustration and improve the legitimacy of the therapeutic work, in order to convey the same message to the client. By assuming a definite and clear role in the relationship and re-establishing clear (but more flexible) boundaries, the therapist led the client to identify her as the main referent in the process of care. In fact, Sofia trusted and relied on the therapist so much that she chose psychotherapy as her primary process of care and stopped tacking anoretic drugs. The client herself provided explicit indicators of the renewed validity of the relationship and during the session stated: 'I only feel at home here. When I got out of the car, I cried for the joy that I was coming here'. Shortly thereafter, the sessions focused on the process of identifying and making explicit with the client the elements that make the therapeutic relationship positive for the client, what it means 'to feel at home' for her and what it is that makes her feel at home, and by contrast, what it is about relationships outside the clinical setting that they do not make her feel the same way. Once more, then, the critical point was to use the emotions that surfaced in therapy to disrupt the system and move it to a higher level of awareness (Guidano, 1991; 1995). Using these emotions in a generative way allowed creating a new theme between the client and the therapist that permitted the latter to start working with Sofia on what it means for her to make requests of others. This topic was further developed to include what it means for her to trust and rely on others, what happens or how she feels when others do not respond to her demands, or do not respond to the extent that she would like them to (a key work plan for clients with an outward-contextualized 
style of organizing their experiences and emotions). Thus, explicitly processing the relationship and its emotional fluctuations has been an important mechanism for repairing the alliance (Hill and Knox, 2009).

An important factor of change in the post-rationalist approach is reconstructing the self, which is measured by reducing the divergence between the actual and the ideal self and by integrating discrepant events and emotions. Overall, the client and the therapist judged the therapy as successful, with a number of changes at Sofia's behavioral and structural level, and symptomatic behaviors eventually moved into a normal range. At the end of the first year of therapy, she reported that her eating symptomatology had reduced significantly; and at the end of the therapeutic process, both the client and the therapist considered the outcome positive. The in-session activity, which focused on defining clear interpersonal boundaries, resulted in the client feeling less distressed by the emotional fluctuations she experienced in her relationships with others. Moreover, she became firmer and clearer about what she needed and in defining her perspective, which improved her self-confidence and assertiveness. She gained greater awareness of her way of functioning and giving meaning of her experiences. She found herself a new hobby (a Latino-American dance course at a local community center) and made time for herself without feeling selfish and bad about it. Towards the end of the therapy, Sofia gained higher levels of acceptance and validation of unpleasant emotions, which led to a decrease in eating symptomatology.

\section{Treatment implication of the case}

In this paper, we have presented a clinical case through the lens of a constructivist postrational paradigm, which emphasizes the centrality of dynamic processes in constructing the self and interpersonal relations (e.g., a process-oriented methodology), attention to the subjectivity of experiences and meanings, the centrality of emotionality in mental processing and the pivotal role of emotional involvement of both client and therapist in the therapeutic process. We conceive the therapeutic relationship as an interpersonal space actively co-built by the two actors in the relationship. In this shared context, the integration of individual narratives creates a new - higher order - shared narrative in which it becomes possible for the client to (safely) explore his personal attitudes and reformulate his life story. With regard to the case of Sofia, the use of the therapeutic relationship as a tool of exploration to regulate interpersonal distance, to validate the client's emotions and to co-build and strengthen the sense of personal integrity was extensive throughout the various stages of the therapy. Given that 'only feelings can change emotions', the therapeutic relationship is the specific context in which the therapist (strategically oriented perturber) sets off effective events and perturbations that boost a reorganization of the system and help the client to change his perception of self and world (Greenberg, 2004; Guidano, 1991;1995).

Connections, disconnection errors and mismatches are integral parts of every interpersonal relationship, thus they also have to be considered as integral parts of a therapeutic relationship. The possible forms of reparation of a mismatch in the therapeutic relationship are unpredictable and the repair is co-created in the dynamic moment-to-moment (emotional) interaction between the therapist and the client. This process is generative in that it promotes the development of different levels of the therapist-client system. At the individual level, both agents in the relationship might have positive effects because the repair might promote their resistance to stress and the anticipation of positive experiences and might support the development of relational-procedural experience, which shows that it is possible to reconnect with others. At the dyadic-systemic level, it promotes the flexibility and complexity of the connection between the two agents and allows for the structuring of their interpersonal shared space at a higher order of complexity. 


\section{Recommendations to clinicians and students}

In the case of Sofia, the acknowledgement, recognition and processing of emotional fluctuations in the relationship was an important mechanism for repairing the alliance. From the side of the therapist this meant accessing and exploring the emotional distress experienced during the session and allowed using these feelings as indicators of the inner fabric of the ongoing relationship. The therapist's supervision together with self-disclosure of feelings and thoughts about the ongoing (therapeutic) relationship were important steps in solving the impasse and created a new way for the therapist and Sofia to interact (see Henretty and Levitt (2010), for a review of the empirical literature on self-disclosure). This is not to say that the therapist should expect this moment of disagreement and frustration. In fact, as shown in the case formulation the therapist was greatly involved in the (co)construction of such moments and might be considered responsible for their occurrence. Not formulating a clear and shared treatment plan, being overly rigid or engaging in chronic defense, prevents therapists from becoming appropriately tuned with their clients. On the contrary, the therapist needs to be firm and flexible in setting the boundaries of the relationship, but also comfortable with the inner uncertainty of its dynamical properties.

\section{Declaration of Conflicting Interests}

The authors declared no potential conflicts of interest with respect to the research, authorship, and/or publication of this article.

\section{Funding}

The authors received no financial support for the research, authorship, and/or publication of this article.

\section{References}

American Psychiatric Association (2000). Diagnostic and Statistical Manual of Mental Disorders (fourth edition) Washington: D.C.. Trad it.: DSM-IV TR Manuale diagnosticostatistico dei disturbi mentali. Milano: Masson, 2001

Arciero, G., \& Bondolfi, G. (2009). Selfhood, Identity and Personality Style. Wiley-Blackwell.

Balbi, J. (2008). Epistemological and theoretical foundations of constructivist cognitive therapies: Post-rationalist development. Dialogues in Philosophy, Mental and Neuro Sciences, 1 (1), 15-27.

Bertolino, A., Arciero, G., Rubino, Latorre, V., De Cabndia, M., Mazzola, V., Blasi, G., Caforio, G., Hariri, A., Kolachana, B., Nardini, M., Weibege, D.R., \& Scarabino, T. (2005). Variation of human amygdala response during threatening stimuli as a function of 5'HTTLPR genotype and personality style. Biological Psychiatry, 57, 1517-1525.

De Marchis, M. (2008). Restructuring the client's problematic events in generative terms [La riformulazione del problema in termini generative]. Proceedings of the IX Conference on Post-Rationalist Psychology and Psychotherapy. Siena, Italy.

De Marchis, M., \& Barca, L. (2013). From a scattered mosaic to the art of "Kintsugi": a path towards new identity [Da un mosaico andato in pezzi all'arte del "Kintsugi": un percorso verso nuove integrità]. Costruttivismi, 1, 58-66.

Deeks, A. (2003). Psychological aspects of menopause management. Best Practice \& Research Clinical Endocrinology \& Metabolism, 17, 17-31. 
Defey, D., Storch, E., Cardozo, S., Díaz, O., \& Fernández, G. (1996). The menopause: Women's psychology and health care. Social Science and Medicine, 42, 1447-1456.

Dimaggio, G., \& Semerari, A. (2001). Psychopathological narrative forms. Journal of Constructivist Psychology, 14:1-23.

Greenberg, L.S. (2004). Emotion-focused therapy. Clinical Psychology and Psychotherapy, 11, 316.

Greenberg, L.S. (2008). The case of Lisa: An integration and reaction to the process analyses. Psychotherapy Research, 18:6, 677-682.

Greenberg, L.S., \& Pascual-Leone, A. (2006). Emotion in Psychotherapy: A practice-friendly research review. Journal of Clinical Psychology: in session, 62(5), 611-630.

Guidano, V. (1991). Affective change events in a cognitive therapy system approach. In J.D. Safran, M.J. Greenberg (Eds.). Emotion, Psychotherapy and Change. New York, Guilford.

Guidano, V. F. (1995). Constructivist psychotherapy: A theoretical framework. In R. A. Neimeyer \& M. J. Mahoney (Eds.), Constructivism in Psychotherapy. Washington: American Psychological Association.

Guidano, V. (2007). Post-rationalist cognitive psycotherapy [Psicoterapia cognitiva postrazionalista]. Milan, Italy: FrancoAngeli.

Guidano, V., \& Liotti, G. (1983). Cognitive processes and emotional disorders. New York, NY: Guilford.

Henretty, J.R., \& Levitt, H.M. (2010). The role of therapist self-disclosure in psychotherapy: A qualitative review. Clinical Psychology Review, 30, 63-77.

Hill, C.E., \& Knox, S (2009). Processing the therapeutic relationship. Psychotherapy Research, 19 (1), 13-29.

Ioannides-Demos, L.L., Piccenna, L., \& McNeil, J.J. (2011). Pharmacotherapies for obesity: Past, current, and future therapies. Journal of Obesity, 1-18.

Lindeman, S. (2011). Assessing and treating patient with chronic panic disorder using cognitive- constructive psychotherapy. Clinical Case Study, 20, 1-11.

Mahoney, M.J. (2005). Constructive psychotherapy. Theory and practice. New York, Guilford Press.

Mahoney, M.J., \& Granvold, D.K., (2005). Constructivism and psychotherapy. World Psychiatry, $4: 2,74-77$.

Mazzola, V., Marano, G., Biganzoli, E.M., Biracchi, P., Lanciano, T., Arciero, G., \& Bondolfi, G. (2014). The In-Out dispositional affective style questionnaire (IN-OUT DASQ): an exploratory factorial analysis. Frontiers in Psychology, 5, 1-12.

Muran, J.C., \& Safran, J.D. (in press). Therapeutic alliance ruptures. In A.E. Wenzel (Ed.), Sage Encyclopedia of Abnormal \& Clinical Psychology. New York: Sage Publications.

Nardi, B., (2010). Guidelines on the construction of a post-rationalist therapeutic approach. European Psychotherapy, 9, 1, 57-67.

Nardi, B., Arimatea, E., Vernice, M., \& Bellantuono, C. (2012a). How subjectivity can be investigated in the post-rationalist approach: Clinical and psycho-diagnostic tools. International Journal of Psychological Studies, 4, 174-187.

Nardi, B., Arimatea, E., Giovagnoli, S., Blasi, S., Bellantuono, C., \& Rezzonico, G. (2012b). The Mini-Questionnaire of personal organization (MQPO): Preliminary validation of a new post-rationalist personality questionnaire. Clinical Psychology and Psychotherapy, 19, 7890.

Nardi, B., \& Bellantuono, C. (2008). A new adaptive and evolutionary conceptualization of the Personal Meaning Organization (P.M.O.) framework. European Psychotherapy, 8, 1, 5-16.

Neimeyer, R. A. (2000). Narrative disruptions in the construction of self. In J. Raskin (Ed.), Constructions of disorder: Meaning making frameworks for psychotherapy (pp. 207-241). Washington, D. C.: American Psychological Association. 
Neimeyer, R. A., Holland, J. M., Currier, J. M. \& Mehta, T. (2008). Meaning reconstruction in later life: Toward a cognitive-constructivist approach to grief therapy. In D. GallagherThompson, A. Steffan \& L. Thompson (Eds.), Handbook of behavioral and cognitive therapies with older adults (pp. 264-277). New York: Springer Verlag.

Neimeyer, R. A., Woodward, M., Pickover, A., \& Smigelsky, M. (2015). Questioning our questions: A constructivist technique for clinical supervision. Journal of Constructivist Psychology, 1-12.

Picardi, A. (2003). The first steps in the assessment of cognitive-emotional organization within the framework of Guidano's model of the self. Psychotherapy and Psychosomatics, 72, 363-365.

Reda, M.A., Donati della Lunga, S., \& Canestri. L., (2011). Emotional reciprocity in psychotherapy: a postrationalist approach [Reciprocità emotiva in psicoterapia: un approccio postrazionalista]. Rivista di Psichiatria, 46, 292-295.

Rubino, V., Blasi, G., Latorre, V., Fazio, L., D’Errico, I., Mazzola, V., Caforio, G., Nardini, M., Popolizio, T., Hariri, A., Arciero, G., \& Bertolino, A. (2007). Activity in medial prefrontal cortex during cognitive evalutaion of threatening stimuli as a function of personality style. Brain Research Bulletin, 74, 250-257.

Safran, J.D., Muran, J., \& Shaker, A. (2014). Research on therapeutic impasses and ruptures in the therapeutic alliance. Contemporary Psychoanalysis, 50, 211-232.

Salvatore, S., Tschacher, W., Gelo, O.C.G., \& Koch, S.C. (2015). Dynamic systems theory and embodiment in psychotherapy research. A new look at process and outcome. Frontiers in Psychology, 6, 1-2.

Samstag, L.W., BatcheLuiare, S.T., Muran, J.C., Safran, J.D., \& Winston, A. (1998). Early identification of treatment failures in short-term psychotherapy. An assessment of therapeutic alliance and interpersonal behavior. Journal of Psychotherapy Practice and Research, 7, 126-143.

Samstag, L.W., Muran, J.C., Wachtel, P.L., Slade, A., Safran, J.D., \& Winston, A. (2008). Evaluating negative process: a comparison of working alliance, interpersonal behavior, and narrative coherency among three psychotherapy outcome conditions. American Journal of Psychotherapy, 62 (2), 165-194.

Timulak, L., \&Pascual-Leone, A. (2014). New developments for case conceptualization in emotion-focused therapy. Clinical Psychology and Psychotherapy, 619-636.

Zaratti, R., \& De Marchis, M. (2007). Psycotherapy as a generative process [La psicoterapia come processo generativo]. Quaderni di Psicoterapia Cognitiva, 20, 1-13.

\section{Biographical Statement}

Laura Barca is a Cognitive-Behavioural Psychotherapist and a Researcher at the Institute if Cognitive Science and Technologies of Rome. She has a PhD in Clinical and Developmental Psychology at the University of Rome 'La Sapienza'. Her scientific interests includes Computational Psychiatry, Cognitive and Developmental Psychology, Cognitive Neuroscience.

Monica De Marchis is a Psychotherapist with a training in couple and family therapy. Since 2005, she teach Psychology of the Addiction at the School of Specialization in Clinical Psychology of Siena, University of Siena. 